\title{
Student-Centered Teaching Design and Practice of Database Course
}

\author{
Yubei Lin* \\ School of Software Engineering, South China University of Technology, Guangzhou Higher Education Mega Center, \\ Guangzhou, China \\ *Corresponding author. Email: yupilin@scut.edu.cn
}

\begin{abstract}
This paper elaborates the design and practice of database course teaching based on student-centered ideas for non-computer-major students in South China University of Technology, which have weak foundation in computer science. The practical results show that the proposed teaching methods effectively stimulate students' interest, enthusiasm and potential in learning, meanwhile better achieve teaching objectives and improve teaching quality.

Keywords: Student-centered teaching, database course, higher education
\end{abstract}

\section{INTRODUCTION}

With the rapid development of information technology, the amount of information is expanding rapidly. Every student is faced with the problem of data analysis and information processing, no matter what his major is. In order to adapt to the development of the information age, at present, in the higher education of our country, computer education has become the training content of all students of every major which is constantly strengthened. Computer Basis course has been included as the basic course in most colleges and universities. Among them, the Database Technology Application (DBTA) course, as one of the six core courses of the computer basic education, has been included in the key courses for management and construction by many colleges and universities.

Taking South China University of Technology as an example, DBTA course is not only a required course for students majoring in computer related majors, but also a required course for many other majors, such as economic and trade, law, news and media, and food science. For these non-computer-major students, DBTA course is the second computer related course after the University Computer Basis course which they take in the first semester of freshman year. Therefore, their computer foundation is relatively weak and their hands-on ability is poor. Because most of them have not studied the database forerunner courses, such as Programming Language, Data Structure, Discrete Mathematics, Operating System, etc., there are great difficulties in learning database related theoretical concepts. Moreover, relatively few class hours are arranged for DBTA course. Under such condition, how to achieve the teaching goal of cultivating and improving students' awareness and ability of using database technology to manage, process and utilize data and information, as well as the ability of integrating and developing application systems in professional fields is a great challenge for the DBTA course teachers [1].

\section{TEACHING IDEAS}

To make good use of teaching time is the first problem to be solved by teachers who teach database courses to non-computer-major students. In order to fully mobilize the enthusiasm and initiative of students, we must turn to the student-centered teaching mode instead of the traditional teacher-centered teaching mode [2]. In the teaching process, students, instead of teachers, should be the main participants in all aspects of teaching activities. In this paper some student-centered teaching ideas are proposed as follows.

(1) Fully consider the knowledge structure and ideology of the students, tap their interest and potential, and reasonably set the stage learning objectives and general objectives of the course for the students, so that they can play to their strengths in a positive state [3].

(2) With the help of various advanced teaching techniques and tools, design a reasonable teaching plan and organize various forms of teaching activities, so as to create a good learning atmosphere for students and guide their learning and self-awareness in time [4].

(3) Let students participate in the activities of the course evaluation so as to promote their learning ability by evaluation under the effective supervision of teachers.

\section{TEACHING DESIGN AND ORGANIZATION}

The teaching content of DBTA course for non-computer majors in our university mainly includes four parts: introduction to database system, theoretical basis of relational database, SQL and its application, and 
development of database application system. The total class hours are only 40 , including 32 hours of theoretical teaching and 8 hours of experimental teaching. As the class hours are relatively few, we pay attention to practical materials in the course content, instead of pursuing perfection. The teaching content of DBTA course has three characteristics as follows:

(1) Basic. Considering that the majority of students' computer foundation is weak, the course arrangement starts from the beginning, step by step, and the preparatory knowledge involved is explained accordingly.

(2) Advanced. Discard some outdated content, and encourage and guide students to learn some advanced development tools and methods with the help of network resources on the basis of mastering basic concepts, technologies and methods of database.

(3) Practical. Based on the standard database language SQL, the application of SQL in Access and some other popular database platforms with examples, as well as some popular practical development technologies of database application system, are introduced in DBTA course.

According to the proposed teaching ideas descripted in the former chapter and the characteristics of the course content, DBTA course teaching is arranged as follows.

\subsection{One Goal}

Most of the students don't understand the question of "why to learn" before class. They don't think that it is useful for non-computer-major students to study computer courses. Therefore, before carrying out teaching activities, it is necessary to eliminate this kind of wrong cognition in students' mind and establish a clear learning goal for them, which is cultivating and improving students' awareness and ability of using database technology to manage, process and utilize data and information, as well as the ability of integrating and developing application systems in professional fields, so as to enhance the motivation of learning this course.

In the first lesson of DBTA course, the teacher can illustrate the application of database technology in the relevant professional fields according to the students' major, so that students can realize that after learning this course, they can not only improve their information processing technology and ability, but also have the consciousness and even the ability to use what they have learned to put forward solutions for the development of application systems in their professional fields in the future work.

\subsection{Two Axes}

Teaching activities are organized with two axes as the cores: one axis is a big assignment of development and design for a database application system, the other is a case explanation in classes.
The purpose of the big assignment is to strengthen the learning objectives of the course and improve the students' practical ability [5]. From the first class, 3-4 students are divided into a team [6], and a team leader will be elected, who is responsible for organizing team discussion in class and joint learning activities after class. Each team is assigned a task, which is to design and develop a database application system, while the topic and the development tool are not limited. The source code of system and a project development report are required to be submitted at the end of the course. The format of the project development report is required to be written in accordance with the format template of graduation thesis, and the content shall include: (1) project planning, in which the purpose and functions of the system, each student's contribution for the project, and the development schedule is indicated. (2) requirements analysis, which should include the data flow chart and the data dictionary. (3) overall design, in which the ER chart should be drawn, the relationship mode should be given, and the paradigm should be optimized. (4) detailed design, in which user interface should be designed and the code of key functions should be illustrated; (5) summary, which should summarize the development experience and shortcomings of the developed system, and look forward to the direction of improvement.

After the release of the big assignment, although students have a clear goal, it seems that the goal is far away. Students may feel that it is an impossible task for them. Therefore, teachers can divide the overall goal of this course into several phased goals. In the theory teaching classes, a case design from the familiar field in life runs through the whole teaching process [7-8]. In the case explanation, the development task is decomposed into small problems corresponding to the key knowledge points such as ER diagram design, the transformation from ER diagram to relational model, the normalization of relational model and SQL query design. In the teaching process, students are guided to solve these small problems one by one, and complete part of the big assignment every week. In this way, not only task accumulation can be effectively prevented, but also students can gradually master the steps and methods of database system design and development.

In addition, in the course of theory teaching, the teacher's teaching, as well as students' discussion and on-the-spot problem-solving are adopted, so as to increase the interaction between the teacher and students in the classroom, which makes students more focused on classroom learning, and cultivate students' thinking ability. More questions can be set up for students to think and discuss, so that the passive learning of students in the traditional class can be changed into the active learning in the discussion class. After class, students are required to summarize what they have just learned with mind maps weekly and upload them to the course teaching QQ group, in order to guide students to sort out knowledge in time and prevent the accumulation of difficulties. 


\subsection{Three-Way-Integrated Evaluation}

Scientific evaluation is an effective way to promote learning. In this course a three-way-integrated course assessment mechanism is adopted, which comprehensively evaluates the performance of students in class discussion and question answering, database application system design and development, and final examination [9-10]. Among them, the first part focuses on the investigation of students' learning process and homework completion, accounting for $20 \%$ of the total evaluation. The second part focuses on examining students' awareness and practical ability to manage, process and use data and information by using database technology, accounting for $30 \%$ of the total evaluation. And the final examination focuses on the students' mastery of the theoretical knowledge of database concept, accounting for $50 \%$ of the total evaluation.

In order to let students participate in the evaluation of teaching activities, each team is required to record a small video of no more than 3 minutes to show the results of the big assignment and upload it to the experimental management system which is independently developed by our teaching group. For each video, 5 students from other teams can rate it via the experiment management system. The scoring rules are as follows: the full score of each work is 60 points, including 10 points for software interface friendliness, 10 points for data addition, deletion and modification functions respectively, 10 points for data query function, and 10 points for users' authority management function. In the process of peer review, if one of the five scores of each video deviates from the average by $20 \%$, it will be invalid and should be re-evaluated. Finally, the highest and lowest scores of the five scores are removed and then averaged, and the score evaluated by students, denoted by $\mathrm{S}$, can be obtained. This score-computing process is automatically realized by the experiment management system.

The teacher is responsible for evaluating the project development report submitted by each team. A score, denoted by $\mathrm{T}$, will be given by the teacher according to the following standards: 10 points for the project planning part, 20 points for the database design part, and 10 points for the system development and implementation part. Add $\mathrm{S}$ and $\mathrm{T}$, and get the score $\mathrm{G}$ of each team. In order to fully mobilize the learning enthusiasm of each student and avoid any students' unearned gains, each member's contribution for the assignment is required to be recorded in the report. According to it, the teacher can multiply $\mathrm{G}$ by an adjustment coefficient $\alpha$, the value of which is between 0 and 1 , to get the score $\mathrm{H}$ of the big assignment of each student.

In order to increase the chance for students to exchange their learning experience, 5 teams with the highest score $\mathrm{G}$ are invited to show their excellent works in the last class. The teacher, as the host, encourages the audience to ask questions. This activity further expands the vision of students, and promotes their thinking more divergent and active. On the basis of $\mathrm{H}$, the teacher can also give no more than 5 bonus points, as an incentive factor to stimulate the students' spirit of hard-working, to the students who have made excellent works according to their exhibition performance.

\section{PRACTICE EFFECT}

After the course, students can evaluate the teaching quality of the course through the educational administration management system. Table 1 shows the specific evaluation indexes and its meaning.

Table 1 Evaluation items

\begin{tabular}{|c|c|}
\hline Index & Evaluation Item \\
\hline 1 & The teacher is concerned about my study. \\
\hline 2 & The teacher is proficient to give a lesson. \\
\hline 3 & $\begin{array}{c}\text { The teaching content is substantial, the arrangement is reasonable and the emphasis is } \\
\text { prominent. }\end{array}$ \\
\hline 4 & $\begin{array}{c}\text { The teacher adopts various teaching methods to carry out teaching, is good at inspiring } \\
\text { and guiding students, and effectively motivates my interest in learning. }\end{array}$ \\
\hline 5 & $\begin{array}{c}\text { The teacher pays attention to the communication and interaction with the students and has } \\
\text { good communication skill. }\end{array}$ \\
\hline 6 & $\begin{array}{c}\text { The teacher is willing to answer questions and solve doubts both inside and outside the } \\
\text { class. }\end{array}$ \\
\hline 7 & I think it's very rewarding through the course. \\
\hline
\end{tabular}

Table 2 Implementation effect of the proposed teaching methods

\begin{tabular}{|c|c|c|c|}
\hline & Before & After & Improvement \\
\hline Number of students & 16 & 39 & \\
\hline Evaluation on Index 1 & 4.438 & 4.590 & 0.152 \\
\hline Evaluation on Index 2 & 4.250 & 4.385 & 0.135 \\
\hline Evaluation on Index 3 & 4.375 & 4.513 & 0.138 \\
\hline Evaluation on Index 4 & 4.250 & 4.564 & 0.314 \\
\hline
\end{tabular}




\begin{tabular}{|c|c|c|c|}
\hline Evaluation on Index 5 & 4.438 & 4.564 & 0.126 \\
\hline Evaluation on Index 6 & 4.188 & 4.615 & 0.427 \\
\hline Evaluation on Index 7 & 4.375 & 4.564 & 0.189 \\
\hline Score for teacher & 4.383 & 4.665 & 0.282 \\
\hline
\end{tabular}

For each evaluation index in Table 1, students can choose "fully agree", "agree", "basically agree", "disagree" or "totally disagree". These options correspond to 5 points, 4 points, 3 points, 2 points and 1 point respectively. The average value of the effective evaluation index reflects the students' evaluation of the teacher in this evaluation index as a whole. The educational administration management system weights the scores of all evaluation indexes in Table 2 to get the scores of the students for the teacher.

Table 2 shows the teaching quality evaluation data of DBTA course extracted from the educational administration management system before and after the implementation of the proposed teaching measures. It can be seen from Table 2 that after the implementation of the teaching methods, students' evaluations on various indicators have been improved to varying degrees. Among them, the evaluation scores of students on Index 4 and 6 are significantly improved, which shows that the implementation of "student-centered" teaching program can more effectively stimulate students' interest in learning, and students asked more questions in such a circumstance.

At the same time, evaluation score of students on Index 7 is also improved, which shows that DBTA course teaching based on student-centered ideas was recognized by the students. In addition, many students wrote in the final summary part of the project development report that at first they thought it impossible to complete the big assignment, but through a semester of study and team cooperating, they finally completed the big assignment, which is an impressive process of learning and exploration. Although there are still many things to be improved in the big assignment, the ability of autonomous learning and hands-on ability has been improved and self-confidence has been strengthened.

With the help of student-centered teaching ideas, the students' score for the teacher is over 4.6, with an overall increase of 0.282 , which further reflects that the proposed teaching methods can improve the teaching quality of DBTA course and promote the students' satisfaction to the course.

\section{SUMMARY}

In the process of teaching DBTA course to non-computer-major students with weak foundation in computer science, the teacher can change from the leader of the classroom to the guide, and let students become the main participants in all aspects of teaching activities. This paper elaborates the design and practice of DBTA course teaching with student-centered ideas and the practice based on them. The practical results show that they can effectively stimulate students' interest, enthusiasm and potential in learning, meanwhile better achieve teaching objectives and improve teaching quality.

\section{ACKNOWLEDGMENT}

This research was financially supported by the Undergraduate Education Research and Education Reform Project of South China University of Technology 2018 and the Undergraduate Distinctive Courses Project of South China University of Technology 2019.

\section{REFERENCES}

[1] Y. Qin, A new teaching method about Database Principle and Application course oriented non-computer professional in college, Education Teaching Forum, (37) (2016) 248-250.

[2] X.J. Liu, On the student-centered ideal, Journal of Higher Education, 33(8) (2012) 1-6.

[3] Fan Chen, How to make student-centered teaching possible__ an empirical study on the status quo of undergraduate classroom teaching in 51 universities, Journal of Higher Education, 38(10) (2017) 75-82.

[4] M.P. Renate, H. Andreas, Student-centered teaching meets new media: concept and case study, Educational Technology \& Society, 5(4) (2002) 160-172.

[5] Robbert, M. Ann, Enhancing the value of a project in the database course, ACM SIGCSE Bulletin, 32(1) (2000) 36-40.

[6] S. W. Dietrich, S. D. Urban, A cooperative learning approach to database group projects: integrating theory and practice, IEEE Transactions on Education, 41(4), (1998) 346-346.

[7] M. Boyeena, P. Goteti, Promoting active learning through case driven approach: an empirical study on database course, 2010 IEEE Students' Technology Symposium (TechSym), (2010) 191-195.

[8] C.X. Wang, G.Q. Liao, X.P. Liu, A.H. Liu, and J.H. $\mathrm{Wu}$, Teaching reform of Database System Principle course for innovative learning, Computer Education, 11 (2017) 23-27. 
[9] X.R. Liu, On teaching reform and practice of Access database technology based on CDIO under the Internet plus mode, Journal of Higher Education, 9 (2018) 9-11.

[10] H. Qiang, Z.W. Li, S.H. Wu, Exploration of practical teaching assessment method in colleges and universities, Experimental Technology and Management, 6 (2018) 170-173. 